\title{
Care strategies adopted by nurses for the implementation of Psychosocial Care Centers*
}

\author{
Estratégias de cuidado adotadas por enfermeiros na implantação de Centros de Atenção \\ Psicossocial
}

Gizele da Conceição Soares Martins ${ }^{1}$, Maria Angélica de Almeida Peres ${ }^{1}$, Leila Brito Bergold ${ }^{1}$, Tania Cristina Franco Santos ${ }^{1}$, Paulo Joaquim Pina Queirós ${ }^{2}$, Antonio José de Almeida Filho ${ }^{1}$

Objective: to understand nursing care strategies during the implementation of the Psychosocial Care Centers. Methods: this is a qualitative research with a social-historical approach, whose primary sources were written documents and seven oral statements. Results: the care strategies evidenced were: integration in the team; organization of the work process; study group; interdisciplinary action; workshops; use of light care technologies. Conclusion: the strategies were in agreement with the Brazilian Psychiatric Reform movement and reinforced that the nurse was a fundamental member in the team for the development of the deinstitutionalization and psychosocial rehabilitation with the patients of the Psychosocial Care Centers researched.

Descriptors: Nursing; Strategies; Mental Health Services.

Objetivo: compreender as estratégias de cuidado de enfermeiros durante a implantação de Centros de Atenção Psicossocial. Métodos: pesquisa qualitativa, de abordagem histórico-social, cujas fontes primárias utilizadas foram documentos escritos e sete depoimentos orais. Resultados: as estratégias de cuidados evidenciadas foram: integração na equipe; organização do processo de trabalho; grupo de estudos; atuação interdisciplinar; realização de oficinas; utilização de tecnologias leves do cuidado. Conclusão: as estratégias estavam de acordo com o movimento da Reforma Psiquiátrica brasileira e reforçaram que o enfermeiro era membro fundamental na equipe para o desenvolvimento da desinstitucionalização e reabilitação psicossocial junto aos usuários dos Centros de Atenção Psicossocial pesquisados.

Descritores: Enfermagem; Estratégias; Serviços de Saúde Mental.

\footnotetext{
*Extracted from the thesis: "O centro de atenção psicossocial como espaço de afirmação do habitus profissional do enfermeiro na saúde mental do município de Volta Redonda", Universidade Federal do Rio de Janeiro, 2017.

${ }^{1}$ Universidade Federal do Rio de Janeiro. Rio de Janeiro, RJ, Brazil.

${ }^{2}$ Escola Superior de Enfermagem de Coimbra. Coimbra, Portugal.

Correspoding author: Antonio José de Almeida Filho

Rua General Polidoro, 58/1306. Botafogo - CEP: 22280-005. Rio de Janeiro, RJ, Brazil. E-mail: ajafilhos@gmail.com
} 


\section{Introduction}

The care for people with mental disorders has undergone changes with the Psychiatric Reform movement in Brazil since 1978. The National Mental Health Conferences and government actions in the 1990s have led to changes in the care model, until then only centered on the hospital mental basis for a territorially based model with the Psychosocial Care Centers ${ }^{(1-2)}$.

The nurse is fundamental in the composition of the Psychosocial Care Centers team with a mandatory presence in the minimum team ${ }^{(3)}$. The process of care from the substitutive services had a direct impact on nursing work, because, in the psychiatric hospital, it was centered on the biomedical model and, in the Psychosocial Care units, it was centered on the psychosocial care, in which acting in a multi-professional team with an interdisciplinary approach was foreseen $^{(1-2)}$.

In the hospital-centered model, the nurse was responsible for the team of nursing technicians, whose main function was to develop technical and bureaucratic activities, such as controlling and administering medications; food and hygiene; checking vital signs; disciplining patients in wards; and organizing the environment $^{(2,4)}$.

The substitution model for the asylum led to the development of other practices, associated to the establishment of a therapeutic relationship due to those of traditional psychiatry, which were insufficient for patients demands, whose results over the years were a high degree of chronification ${ }^{(4-5)}$.

The nurse needed to have other care strategies to act in a Psychosocial Care device, such as relational technologies - bonding, fostering, and co-responsibility. Working only with traditional and technicist practices linked to the hospital-centered model implied a risk of reproducing the asylum context in a psychosocial rehabilitation service ${ }^{(2-6)}$. The use of subjective tools is part of a complex but less technical treatment, in accordance with the Psychiatric Reform movement ${ }^{(2,5)}$. In this context, the municipality of Volta Redon- da located in the south of the State of Rio de Janeiro, Brazil, has undergone changes in the care setting for people with mental disorders, starting in 1995 that it was the year of creation of the first Psychosocial Care Center for adults in the municipality - Usina de Sonhos. The second device for adults was launched in 1999, known as Vila Esperança ${ }^{(7)}$.

However, Volta Redonda showed a different position regarding the nurse's role in these extra-hospital devices that in addition to the use of light technologies, other strategies of care were used, pertinent to the precepts of the Psychiatric Reform, moving away from the focus of the disease, so typical of the biomedical model. This fact was driven by the political leadership that prevailed in the municipality during this period, going against the Psychiatric Reform movement.

Therefore, this research aimed to understand nurses' strategies of care during the implantation of the Psychosocial Care Centers of Usina de Sonhos and Vila Esperança, in the municipality of Volta Redonda. Thus, the guiding question was: which care strategies have nurses adopted in the process of implantation of these first Psychosocial Care Centers?

\section{Methods}

This is a qualitative research with a historical approach $^{(8)}$, which deals with the history of the present time, since it does not consider that "history is only a study of the past, but also it is a study of the present with a smaller retreat and particular metho$\mathrm{ds}^{\prime \prime}(9: 28)$.

The study period is from 1995 with the creation of the first Psychosocial Care Center of the city of Volta Redonda, Rio de Janeiro, Brazil to 2002, with the accreditation of the Usina de Sonhos and Vila Esperança devices with the Unified Health System.

Seven oral statements were the primary sources used in this study. The interviews had an average duration of 45 minutes, they were digitally recorded and later transcribed and validated by the partici- 
pants, after reading and written authorization of the study participants. They were held after signing the Free and Informed Consent Term, certified they had no doubts about the development of the research and its objectives. The interview place was defined by the participants and took place in the work environment. They were guided by a script with open questions about the subject in question, such as the participation in the implementation process of the Psychosocial Care Centers; challenges and achievements in this process; selection criteria, stocking and qualification of human resources.

The participants' working time varied from three to 15 years, with four participants working only at the unit called Usina de Sonhos, two in the Unit identified as Vila Esperança and one in the coordination of the Mental Health Program. Four participants had experience in the management of these extra-hospital devices and two had teaching functions in a higher education institution with curricular activities in these devices.

The identification of the participants of the research was the initial corresponding to the profession and the sequential number of the interview order nurses (NUR1; NUR2; NUR3; NUR4); nursing technique (NT); social worker (SW); psychologist (PSY). The inclusion criterion adopted was: management and care professionals who worked at the Psychosocial Care Centers in the multi-professional teams. Professionals who did not experience the implantation process in at least one of the Psychosocial Care Centers in the municipality of Volta Redonda, or who had not acted in the management of the implementation process of these devices, were excluded from the survey.

For the analysis of the documentary corpus, active procedures of interrogation of the documents were adopted with an independent position of the official version and, thus, better evidence of the historical phenomenon.

The reliability of the results was ensured by the valorization of the documentary set, typical of historical research, and not the documents alone. Also, the chronology of events during the period investigated was considered.

The data were analyzed based on articles and books on the topic, with emphasis on the internationally known concepts of deinstitutionalization and psychosocial rehabilitation. Thus, it is understood that deinstitutionalization is a process that must reach out to the people of society in terms of abandoning culturally diffused concepts as well as practices of the biomedical and asylum model characteristic of traditional psychiatry ${ }^{(1,5,10)}$.

The study met all the formal requirements contained in the norms of research involving human beings, through Resolution 466/12, and proved according to opinion no $1,041,681$.

\section{Results}

The Psychosocial Care Center depends on the presence of material and human resources, and on how to develop care. In this perspective, the professionals who composed the human resources of the Psychosocial Care Centers Usina de Sonhos and Vila Esperança understood the importance of integrated work in a team.

The activities of the nurses at the Usina de Sonhos Unit, which included care to the patient and the service organization showed that the care provided was not based only on technical activities and depended on the professional teamwork. It was a large team that worked on two mini-computers. I had a group of patients who were my reference, from my mini-computer and the other nurse had her reference group. We worked on different days, but on Wednesday we worked together because we also needed to discuss things that had to do with our service (NUR2).

The activities nurses of these extra-hospital devices was not characterized by the predominance of bureaucratic and procedural actions, focused exclusively on medication administration, records in medical records, among others. There were activities together with other professionals, according to these statements: We actually worked together, outside the specific procedu- 
res of nursing... but, the nurse was inserted in all processes of care of that service... The basic process of nursing as a request for medication, this bureaucracy, this was done by the nurse. So I did it, even because, in the category, you need to have a technical manager. So, I was the technical responsible, but in the administrative part, now; not in the assistance part, we did not have a directed action, it was all together (NUR3).

Thus, the following statements clarify how nurses were involved in teamwork, participating in individual care, in a group, and in workshops, hosting and elaborating a therapeutic project, besides to specific nursing activities: ...The intervention model and the performance of this nurse was well differentiated from the hospital and he was not restricted to the medication of this patient, despite supervising and everything, he did the care, consulted, participated in the group, did everything the team did, so he worked in therapeutic design and not in that mental health model of giving food, medicating, avoiding being aggressive, controlling that person's emotions and not controlling emotions (NUR4). Every professional has his own exercise, according to their training, but the mental health professional is a different professional, he has to be a different professional, he has to walk together, what is specific to him, something that belongs to everyone, it is a behavior of the mental health professionals... What I say is the mental health professional goes beyond of his profession. So I had a day in a group, a day that was in the workshop, a day in the reception group, a day on duty call to meet the urgencies that arrived (SW).... I did a little of everything, except what was specific to another category, for example, psychologists did not administer medication and nurses did not do psychotherapy and psychologists did, I'm giving an example, but it was the specific to each profession, the nurse did everything (PSY). He had a specific nurse at the Psychosocial Care Center, because these patients were still very chronic, very dependent on medication, used many medications, had the nursing center, the pharmacy that distributed the medication to them. They had guidance, a medication counseling group, with the intention of developing autonomy, so they would take the medication alone. Morning, afternoon, night, many of them could not read, so I remember we made a moon, a star, and the sun was the morning. So, being close to that patient, showing him what that medication was, how he was going to use it, that was specific to nursing (NUR1).

It should be noted that in 1999, the assistance to consider the uniqueness of the patient was not a common practice, but in both Psychosocial Care Centers, there were nursing professionals with behavior consistent with the deinstitutionalization movement and rehabilitation practices: One thing that I have learned a lot in those years, all working with mental health, is valuing the individual as a human being, if we can do that, we can actually transform their lives and our lives, because it is a matter of valuing, of believing in the other as subject of one's life. If we can do this, all other things come together... I think the collaboration process is fundamental for both parties, and we learn a lot from people and people learn a lot from us (NUR3). So, you see that the person has a difference. So for me, within the limitation that disease causes, the person learns to adapt and live productively with the limitation... (NUR2).

For nurses, the focus was on the exchange between the professional and the patient, valuing him and configuring the therapeutic relationship as a strategy of care in mental health in the psychosocial care devices of the municipality of Volta Redonda.

The therapeutic relationship also contributed to transforming the act of administering injectable drugs - private to the nursing team - in a welcoming practice by the nurse of the Psychosocial Care Center: So, precisely those patients who were undergoing injecting procedure, of violence, was because it was resistant to the oral medication, they already had a certain degree of difficulty, it was the most difficult moment that we understood for him, he was going to be invaded by a needle. So, there should be a more convincing act, listening, welcoming than the perforation, puncturing anyone does, it should not be so, then it should be medicating him, in a way that he understood the need, the benefit of that medication. And then, this is the nurses' role (NUR1).

The following statements show the diversity of activities carried out by the nurse at the Vila Esperança Psychosocial Care Center, focused on psychosocial rehabilitation: I remember that the nurse did a workshop, a home visit, she did something about everything, in general, it was in double and administered medication, there was nursing center, very simple. In the health center, drugs were administered (PSY). She did a painting workshop, a city recognition workshop, a beauty workshop. Most of her schedule here in the unit was practically one of intensive care 
with the patient. He took care of the nursing, yes, but especially in the matter of workshop, of conversation, of being with the patient... she was the person who performed the most workshops (NT).

There are statements that highlight the attempt to make the nurse return to an institutionalizing position, in a commonplace, with bureaucratic tasks, a retrocession to the rehabilitative view in development. The following statements reinforce it: The Vila Esperança Psychosocial Care Center was something I did not know how we could work there, there were many patients inside that house really crashing, but I remember, it was the nurse, circulating in this house, asking questions when they delegated this bureaucratic place to her. I remember her a lot, always asking, and that brought a lot of trouble for her, because some people could not see it any other way, and they wanted to bring her to this place of the procedure, the injection, the supervision, and she was there, in the coexistence, in the workshop, accompanying cases (PSY).... she, the nurse, was one of the collaborators for the people who were arriving, the technicians, and the nurse he was just another reference technician, he did not put himself in the place of the nurse, he did not stay in place to supervise the nursing technician who was here, we were a work colleague. And, of course, we gave the medication, a superficial dressing, but the biggest question is to get involved with the service in general (NT).

The development of the Study Group of the Psychosocial Care Center at the Usina de Sonhos was an initiative of the service professionals who, due to the integration, in the quest for quality care and in accordance with the principles of the Psychiatric Reform, they created this resource, with the purpose of instrumentalizing, discussing and building knowledge in an interdisciplinary way. This Group began as soon as the Psychosocial Care Center Usina dos Sonhos started, but it was regularly established by the professionals in 1998: ...Once a week, we had a meeting, but not just a meeting, it was a study group too, and there, we were always working on issues related to mental health and care. From the beginning, we were never without it, we always guaranteed this space (SW). When I entered the Psychosocial Care Center, this was already being said [Psychiatric Reform], and then with the time, even by the very question of the reform, it intensified in the study groups... So, a member of the team had a theme, he discussed this theme and the whole team participated in this topic discussion, but it was presented by one person (NUR3).

In the Vila Esperança device, the study group proposal was not so successful due to the peculiarities of the device, as the statements explain: We started to have a practice, it was even proposed by me, to read texts, we distributed the text during the week, half an hour before the meeting, then we discuss the text a little bit, because, you have a view, you see what people are thinking, in what way, because you see an object from an angle is one thing, from another angle is another, and each one has an angle, a point of view for us to try to understand, and then it lasted for a while, it was very cool, but with the turnover, the employee shortage, it was over (NUR1).

\section{Discussion}

The interviewees' statements showed that the nurses of the Psychosocial Care Centers Usina de Sonhos and Vila Esperança sought new ways of acting to comply with the principles of the Psychiatric Reform and reaffirming the importance of performing the assistance included in the teamwork interdisciplinary and focused on deinstitutionalization and psychosocial rehabilitation.

The Psychiatric Reform disagrees with the plastering and the institutional rules of the asylum. Planning and organizing the service is different from the pre-defining activities without considering the several variables that permeate patients' lives. A quality service in mental health needs to have good integration in the members and with contact with other services that can contribute to improving the quality of life of the patients and the family ${ }^{(1,10)}$.

When performing activities in public health services, there is often a shortage of material resources, which becomes a justification for not performing essential activities. In the case of Psychosocial Care Centers, the shortage of materials for workshops is an aspect that hinders the functioning of activities ${ }^{(11)}$. However, in the period of implementation of these Psychosocial Care Centers, this impediment did not 
prevent the development of care activities, due to the commitment of the nurses to the process of psychosocial rehabilitation.

The teamwork is one of the challenges found in mental health. A quality mental health service is developed by the integration of the members, and also by knowing limits and permeability of the actions, characterizing the interdisciplinary care ${ }^{(2,11)}$.

A research carried out in Singapore pointed out that one of the challenges of achieving an integrated multi-professional team is to have professionals engaged in building forms of care that add knowledge of each other's profession, that is, something that each individual profession is not able to do. Thus, it is evident the importance of interdisciplinary work in mental health, and it is necessary to construct care collectively ${ }^{(12)}$.

The professionals who worked in these Psychosocial Care Centers in Volta Redonda needed to use interdisciplinary work as logic of organization of the work process. They exchanged knowledge and nurses were able to share specific knowledge of the profession with the other members, maintaining the perspective of the Psychiatric Reform.

The work process became the legitimization of an interdisciplinary team, maintaining attributions and specificities, and to stimulating the exchange with other professionals for a common knowledge and integral care, without hierarchy and promoting learning to deal with new situations, built together ${ }^{(13)}$.

Another difficulty was to confront the indication that nursing should be responsible only for bureaucratic and organizational tasks of the mental health service. Often, such an appointment occurs on the initiative of members of other professional categories, who are unaware of the nurse's training. The resistance to innovations in care practices happens because specific skills or subjective tools inherent to nursing are not developed throughout the training process ${ }^{(6)}$. In Palestine, this was also identified in a study that revealed the difficulty of nurses developing new practices, with no local government support, and many felt excluded by other team members ${ }^{(14)}$.

However, the empowerment resulting from the new nursing practices that promoted the expansion of mental health knowledge in Volta Redonda, Brazil still in the 1990s, allowed the nurses of the Psychosocial Care Centers to occupy positions, considered fundamental for the functioning and assistance to patients.

It is important to highlight the nursing when prioritizing relational technologies of care, such as bonding, fostering, co-responsibility, developing competencies to contemplate the multi-dimensions and complexities of the person with mental disorders biopsychosocial, spiritual, economic and cultural ${ }^{(4-6,15)}$.

Listening and acting therapeutically through the relationship established with the patient were strategies used and in accordance with creative and sensitive mental health care. Also, therapeutic communication should be considered as an important resource for performing technical procedures, through bonding and trust between the nurse and the patient. Professional involvement is fundamental in the performance of technical procedures - considered stressful situations for the patient - and relational technologies have proved to be allies in improving care and psychosocial rehabilitation of the patient ${ }^{(15)}$.

The involvement of professionals and patients in the Psychosocial Care Centers in the collective construction of treatment is a strategy that has been used in many developed countries. Although Brazil is considered a developing country and Volta Redonda is a city away from large urban centers, mental health professionals, especially nurses, did not reproduce a model in which the patient is considered passive. This is similar to the care provided by nurses in the United Kingdom, whose treatment is planned and built together with the patient ${ }^{(10)}$.

The study group to train and empower nurses is highlighted since it was a new situation in which there was no preparation to work during the professional training, nor had they participated in any training course. The study group helped them to update knowledge and could be considered a permanent edu- 
cation of their own initiative and without government support. A study with Taiwanese psychiatric nurses ${ }^{(16)}$ shows that the lack of continuing education in the services where they performed left them unconfident to participate actively in the management of cases of patients with mental disorders.

Thus, as seen in this research, other studies point out that the fact of perceiving the person with mental disorder, through a rehabilitation proposal and not focused on the disease and the remission of symptoms, has guided public policies on mental health in several places of the world ${ }^{(10,12,14,16)}$.

\section{Conclusion}

The nurses of the centers investigated developed strategies of nursing care in mental health, according to the perspective of the Psychiatric Reform. There was a priority working in an interdisciplinary team, safeguarding the importance of the specific knowledge of each profession. It is noteworthy that the nurses were able to affirm the professional qualification, through the active search of knowledge and accomplishment of a group of studies in service.

\section{Collaborations}

Martins GCS contributed in the project and design, analysis and interpretation of the data. Peres MAA, Bergold LB, Santos TCF, Queirós PJP and Almeida Filho AJ collaborated with the writing of the article and critical and relevant review of the intellectual content. Martins GCS and Almeida Filho AJ helped in the final approval of the version to be published.

\section{References}

1. Almeida Filho AJ, Fortes FLS, Queirós PJP, Peres MAA, Vidinha TSS, Rodrigues MA. Trajetória histórica da reforma psiquiátrica em Portugal e no Brasil. Referência. 2015; 21(4):117-25. doi: http://dx.doi.org/10.12707/RIV14074
2. Maftum AM, Silva AG, Borba LO, Brusamarello T, Czarnobay J. Changes in professional practice in the mental health area against brazilian psychiatric reform in the vision of the nursing team. Rev Pesq Cuid Fundam on line. 2017; 9(2):309-14. doi: http://dx.doi.org/10.9789/2175-5361.2017. v9i2.309-314

3. Emmanuel-Tauro DV, Foscaches DAL. As atuais políticas de saúde mental no Brasil: reflexões à luz da obra de Cornelius Castoriadis. Mental [Internet]. 2018 [cited 2018 July 13]; 12(22):90112. Available from: http://pepsic.bvsalud.org/ pdf/mental/v12n22/v12n22a07.pdf

4. Fortes FLS, Peres MAA, Santos TCF, Martins GCS, Montenegro HRA, Almeida Filho AJ. Mental health nurses: conceptions about professional qualification in a Psychosocial Care Center. Rev Rene. 2017; 18(6):763-70. doi: http://dx.doi.org/ 10.15253/2175-6783.2017000600009

5. Lourenço BS, Peres MAA, Porto IS, Oliveira RMP, Dutra VFD. Physical activity as a therapeutic strategy in mental health: an integrative review with implication for nursing care. Esc Anna Nery. 2017; 21(3):e20160390. doi: http://dx.doi. org/10.1590/2177-9465-ean-2016-0390

6. Lima DWC, Silveira LC, Vieira AN, Cunha BMC, Almeida ANS, Guerreiro EM. Theoretical references that guide nursing practice in mental health. Esc Anna Nery. 2014; 18(2):336-42. doi: http:// dx.doi.org/10.5935/1414-8145.20140049

7. Almeida Filho AJ, Queirós PJP, Rodrigues MA. Psychosocial rehabilitation in assisted housing in Brazil and Portugal. Texto Contexto Enferm. 2016; 25(1):1-9. doi: http://dx.doi.org/10.1590/010407072016000770015

8. Padilha MICS, Bellaguarda MLR, Nelson S, Maia ARC, Costa R. The use of sources in historical reserarch. Texto Contexto Enferm. 2017; 14(4):e2760017. doi: dx.doi.org/10.1590/010407072017002760017

9. Delgado LAN, Ferreira MM. História do tempo presente. Rio de Janeiro: FGV Editora; 2014.

10. Longden E, Read J, Dillon J. Improving Community Mental Health Services: The Need for a Paradigm Shift. Isr J Psychiatry Relat Sci [Internet]. 2016 [cited Jul 28, 2018]; 53(1):22-9. Available from: www.ncbi.nlm.nih.gov/pubmed/28856876 
11. Santos SN, Esperidião E, Queiroz BAL, Gonçalves CAC, Silva SAC, Carvalho Silva KK. Perception of nurses about advantages and constraints of their practice in mental health services. Rev Bras Enferm. 2013; 66(5):745-52. doi: http://dx.doi. org/10.1590/S0034-71672013000500016

12. Cai SY, Fung DSS. Community Mental Health as a Population-based Mental Health Approach. Isr J Psychiatry Relat Sci [Internet.] 2016 [cited Oct 28, 2018]; 53(1):33-9. Available from: http://www. redmaristan.org/source/15/IJP\%20Vol\%20 $1 \% 202016 \% 20(2)$ community $\% 20$ psychiatry. pdf\#page $=33$

13. Silva NS, Esperidião E, Gonçalves CAC, Silva SAC, Carvalho SKK. Development of human resources for work in mental health services. Texto Contexto Enferm. 2013; 22(4):1142-51. doi: http://dx.doi. org/10.1590/S0104-07072013000400033
14. Marie M, Hannigan B, Jones A. Challenges for nurses who work in community mental health centres in the West Bank, Palestin. Int J Ment Health Syst. 2017; 11(3). doi: https://doi. org/10.1186/s13033-016-0112-4

15. Bandeira PM, Sousa CHP, Guimarães JCS, Almeida Filho AJ, Peres MAA. Psychiatric nursing in integrated wards accommodating both female and male patients: a historic pioneering reform initiative implemented by the Institute of Psychiatry, a Unit of the Federal University of Rio de Janeiro, Brazil. Issues Ment Health Nurs. 2015; 36(10):791-8. doi: https://doi.org/10.3109/016 12840.2015 .1043674

16. Liu WI. Examining Taiwanese psychiatric nurses' knowledge and confidence in case management. J Contin Educ Nurs. 2014; 45(1):43-8. doi: https:// doi.org/10.3928/00220124-20131015-07 